\title{
Visão geológica dos monumentos da cidade de São Paulo
}

\author{
Eliane Aparecida Del Lama1, Lauro Kazumi Dehira ${ }^{2}$ \& Aranda Calió dos Reys ${ }^{3}$
}

\begin{abstract}
Resumo Este trabalho trata de análise do estado de conservação de monumentos históricos pétreos da cidade de São Paulo. Foram analisados 20 monumentos: A Menina e o Bezerro, Amor Materno, Depois do Banho, Fonte Monumental, Anhanguera, Aretuza, Camões, Cervantes, Fauno, Mãe, Nostalgia, O Ceifador, Monumento às Bandeiras, Duque de Caxias, Glória Imortal aos Fundadores de São Paulo, Monumento a Ramos de Azevedo, Obelisco, Amizade Sírio-Libanesa, Monumento a Carlos Gomes, e Obelisco da Memória. Os monumentos foram estudados do ponto de vista de caracterização dos constituintes materiais, a sua procedência e análise do seu estado de alteração. Para isso foi realizada pesquisa histórica, observações de campo e técnicas analíticas laboratoriais (difratometria de raios $\mathrm{X}$, microscopia eletrônica de varredura com espectroscopia de energia dispersiva de raios $\mathrm{X}$ acoplado e microscopia petrográfica). A grande parte desses monumentos é constituída por mármore ou granito, principalmente o Granito Itaquera e o Granito Cinza Mauá. Os monumentos constituídos pelo Granito Cinza Mauá estão menos degradados. Todos os monumentos, por se situarem em ambientes externos, são afetados por processos intempéricos, com contribuição de micro-organismos e poluição. Foram identificadas as seguintes formas de intemperismo: depósito superficial, incrustação, alteração cromática, manchas, alveolização, colonização biológica, vegetação, eflorescência, concreção, escamação, lascagem, formação de plaqueta, ocorrência de fraturas e fissuras. Além do intemperismo, o que mais degrada os monumentos da cidade de São Paulo é o vandalismo, principalmente as pichações, prejudicando a preservação da nossa herança cultural.
\end{abstract}

Palavras-chave: monumentos, formas de alteração, Granito Itaquera, Granito Cinza Mauá, mineralogia aplicada.

\begin{abstract}
Geological vision of São Paulo city monuments. This research deals with the conservation degree of the stone historical monuments from São Paulo city. The monuments analysed were $A$ Menina e o Bezerro, Amor Materno, Depois do Banho, Fonte Monumental, Anhanguera, Aretuza, Camões, Cervantes, Fauno, Mãe, Nostalgia, O Ceifador, Monumento às Bandeiras, Duque de Caxias, Glória Imortal aos Fundadores de São Paulo, Monumento a Ramos de Azevedo, Obelisco, Amizade Sírio-Libanesa, Monumento a Carlos Gomes, and Obelisco da Memória. This study regards the rock materials, their source and analyse of alteration forms of the monuments, based on historical research, on in situ observations and laboratory analytical techniques (Xray diffractometry, scanning electron microscopy with an energy dispersive spectrometer, and petrographical microscopy). Marble and granite compose the most part of the monuments, mostly Itaquera Granite and Cinza Mauá Granite. The monuments composed by Cinza Mauá Granite are less degradated. As the monuments are placed in outside, they are affected by weathering, microorganism and pollution. Surface deposit, incrustation, chromatic alteration, stain, alveolization, biological colonization, vegetation, efflorescence, concretion, peeling, spalling, plaquette, fracture and fissure were identified in the monuments. Besides weathering, vandalism raise more degradation in the monuments, mainly graffiti, damaging our cultural heritage.
\end{abstract}

Keywords: monuments, alteration forms, Itaquera Granite, Cinza Mauá Granite, applied mineralogy.

INTRODUÇÃO A participação de geólogos em serviços voltados para preservação de monumentos e patrimônio históricos é intensa em todo o mundo. No Brasil, observa-se que essa participação tem aumentado nos últimos anos. Algumas formas de participação dos geólogos para o estudo e conservação de monumentos históricos são apontadas em Del Lama (2006).

Dentre estas contribuições, pela própria formação curricular dos geólogos, destaca-se aqui o estudo dos materiais rochosos dos quais os monumentos são confeccionados, principalmente em relação ao intemperismo das rochas e a identificação da procedência dos materiais rochosos.
Para a exemplificação desta participação de geólogos, é apresentado este trabalho, em que foram selecionados alguns monumentos de constituição pétrea pela cidade de São Paulo, alguns dos quais tombados pelo Patrimônio Histórico Municipal, no qual se apresenta a caracterização dos constituintes rochosos, a sua procedência e análise do seu estado de alteração.

A grande parte desses monumentos é constituída ou por mármore ou por granito. Dentre os granitos, os mais comuns são os tipos Granito Cinza Mauá e Granito Itaquera, que serão abordados a partir de sua constituição mineralógica, as formas de intemperismo presentes e possíveis condicionantes do intemperismo. 
Quando disponíveis, serão apresentados dados analíticos obtidos. Quanto aos mármores, alguns são procedentes da Itália, mas são poucos os monumentos com registro da procedência. De maneira geral, são mármores puros e brancos.

Não é objetivo deste trabalho a proposição de técnicas de restauração, pois projetos de restauração devem ser realizados por equipes multidisciplinares, mas sim, a avaliação do estado de deterioração destes monumentos a título de atuação de geólogos no campo de preservação de monumentos. A etapa de mapeamento das formas de intemperismo deve sempre ser realizada em fases preliminares de projetos de restauro, de forma que se possa planejar as maneiras de se realizar a restauração, além do que, constitui-se em um importante registro do estado de conservação prévio à intervenção.

Desta forma, ilustra-se a atuação do geólogo nesta área, com o fornecimento de dados analíticos para projetos de restauração na fase de diagnóstico, contribuindo assim para a preservação da memória cultural brasileira.

TRABALHOS PRÉVIOS O estado de conservação de monumentos da cidade de São Paulo, do ponto de vista geológico-mineralógico, foi abordado em Reys et al. (2007). No presente trabalho é feita uma complementação com a apresentação de dados analíticos dos monumentos avaliados nesse trabalho, e apontar a procedência da rocha constituinte de alguns desses monumentos. Os dados cadastrais dos monumentos, compostos por fichas com o histórico, o estado de conservação e o registro fotográfico, foi apresentada em Reys (inédito).

Stern et al. (2006) apresentam uma caracterização do revestimento pétreo de alguns edifícios históricos e a proposição de um roteiro turístico-geológico pelo centro velho de São Paulo.

No edifício do Teatro Municipal de São Paulo, o impacto do intemperismo nos arenitos de seu revestimento externo foi tratado por Del Lama et al. (2008), ressaltando a importância da caracterização mineralógica em rochas ornamentais frente às condições ao ar livre em áreas urbanas e às características intrínsecas do material que podem ter contribuído para a aceleração do intemperismo.

Estudos de identificação das formas de intemperismo também já foram realizados em um convento em Vila Velha, ES (Sant'Ana et al. 2002), em estátuas barrocas em Ouro Preto, MG (Silva \& Roeser 2003) e igrejas, no Rio de Janeiro, RJ (Baptista-Neto et al. 2006, Silva 2007) e em Porto Alegre, RS (Philipp \& Di Benedetti 2007).

Teixeira et al. (2008) demonstram a utilização do Martelo de Schmidt na caracterização do estudo de degradação das rochas do pórtico da Igreja de Nossa Senhora da Glória do Outeiro no Rio de Janeiro.

MATERIAIS E MÉTODOS A identificação dos materiais pétreos foi feita visualmente no local, visando sua classificação petrográfica, inclusive das bases em que se situam, assim como o estado de alteração e de conservação atual dos mesmos, incluindo os entornos das obras.
A partir da observação visual, e quando disponível a petrografia dos tipos de rochas constituintes dos monumentos, além de informações disponíveis na literatura, procurou-se inferir a procedência das rochas constituintes dos monumentos.

Foram confeccionadas lâminas petrográficas a partir de amostras dos monumentos estudados. Essas lâminas foram obtidas a partir de fragmentos de rocha de monumentos que foram danificados, e que foram cedidos pelo Departamento de Patrimônio Histórico do Município de São Paulo (DPH) e pelo próprio Teatro Municipal de São Paulo, além das amostras existentes no acervo do Instituto de Geociências da Universidade de São Paulo (IGc-USP). Nos monumentos foram coletadas amostras de deposições superficiais (fuligem e material orgânico), eflorescências, concreções de argamassa e caiação (amostra de cal).

Desta forma, a amostragem em que se baseou o presente trabalho não provocou danos à integridade dos monumentos estudados.

Os métodos analíticos utilizados foram: difratometria de raios X (DRX), microscopia eletrônica de varredura (MEV) com EDS (espectroscopia de energia dispersiva de raios X) acoplado e microscopia petrográfica.

Os difratogramas obtidos via DRX permitiram a identificação das fases cristalinas presentes nas amostras de eflorescências, fuligem e argamassas. As amostras foram analisadas no Laboratório de Difração de Raios X do IGc-USP.

As amostras para MEV foram preparadas com stubes de 1/4" com fita adesiva de carbono ou fita de cobre. As análises foram realizadas no Laboratório de Microscopia Eletrônica do IGc-USP.

A microscopia petrográfica foi realizada no Laboratório de Petrografia do IGc-USP, e a confecção das lâminas petrográficas foi executada na Seção de Laminação do IGc-USP.

OBRAS ANALISADAS Os monumentos estudados são listados a seguir, com informações da autoria da obra, sua localização atual, data de implantação e constituição material (Fig. 1).

1. A Menina e o Bezerro, de Charles Louis Eugène Virion - Largo do Arouche, Centro - 1922 - estátua de mármore com pedestal do Granito Itaquera;

2. Amizade Sírio-Libanesa, de Ettore Ximenez - Praça Ragueb Chohfi, Parque D. Pedro II - 1928 - granito rosa (Rosa Salto, por similaridade petrográfica) e estátuas de bronze;

3. Amor Materno, de Charles Louis Eugène Virion - Largo do Arouche, Centro - 1914 - estátua de mármore com pedestal do Granito Itaquera; recentemente o pedestal foi substituído por um granito porfiroclástico, num programa de restauração de alguns monumentos promovidos pela Prefeitura Municipal de São Paulo e a iniciativa privada;

4. Anhanguera, de Luigi Brizzolara - Avenida Paulista, em frente ao Parque Trianon - 1921 - estátua de mármore oriundo de Gênova - Itália com pedestal de calcário fossilífero; 

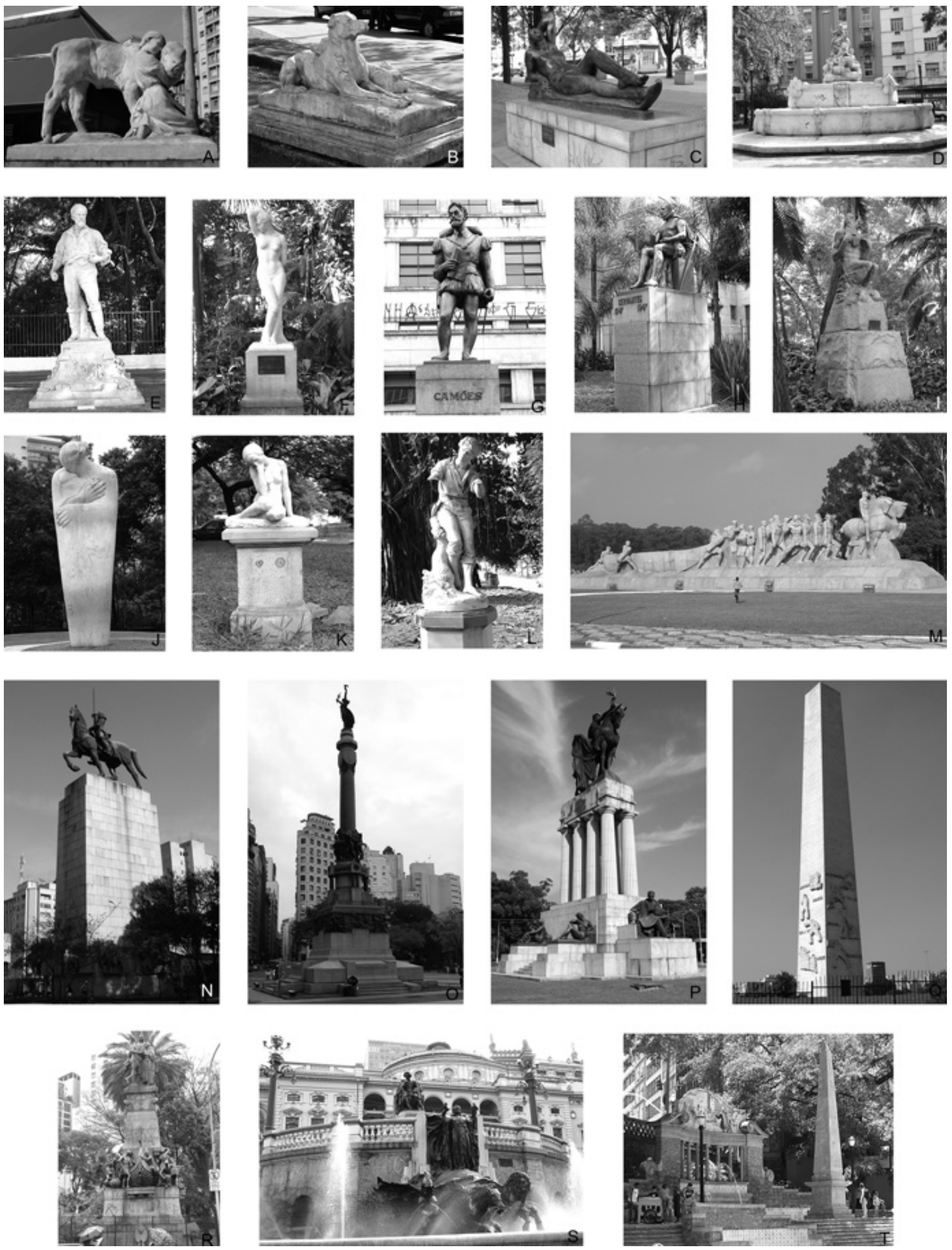

Figura 1 - Monumentos estudados neste trabalho. (A) A Menina e o Bezerro, (B) Amor Materno, (C) Depois do Banho, (D) Fonte Monumental, (E) Anhanguera, (F) Aretuza, (G) Camões, (H) Cervantes, (I) Fauno, (J) Mãe, (K) Nostalgia, (L) O Ceifador, (M) Monumento às Bandeiras, (N) Duque de Caxias, (O) Glória Imortal aos Fundadores de São Paulo, (P) Monumento a Ramos de Azevedo, (Q) Obelisco, (R) Amizade Sírio-Libanesa, (S) Monumento a Carlos Gomes, e (T) Obelisco da Memória.

5. Aretuza, de Francisco Leopoldo da Silva Parque Trianon - nos anos de 1920 - estátua de mármore com pedestal do Granito Itaquera, foi observado na visita realizada em 13/07/2008 que a estátua foi tratada com algum produto impermeabilizante;
6. Camões, de José Cucê - Praça Dom José Gaspar, Centro - 1942 - estátua de bronze com pedestal do Granito Cinza Mauá;

7. Cervantes, de Rafael Galvez - Praça Dom José Gaspar, Centro - 1947 - estátua de bronze com pe- 
destal de granito rosa;

8. Depois do Banho, de Victor Brecheret - Largo do Arouche, Centro - 1941 - estátua de bronze com pedestal do Granito Itaquera;

9. Duque de Caxias, de Victor Brecheret - Praça Princesa Isabel - 1960 - Granito Cinza Mauá e estátua de bronze;

10. Fauno, de Victor Brecheret - Parque Trianon - 1942 - estátua de Granito Cinza Mauá com pedestal do Granito Itaquera;

11. Fonte Monumental, de Nicolina V. A. P. do Couto - Praça Júlio de Mesquita - 1927 - mármore com ornamentações de bronze;

12. Glória Imortal aos Fundadores de São Paulo, de Amadeu Zani - Páteo do Colégio, Centro - 1925 - estátua de bronze com coluna de sienito vermelho e base de granito cinza (parecido com o Granito Cinza Mauá, mas não é porfirítico);

13. Mãe, de Caetano Fracarolli - Praça Buenos Aires, Higienópolis - 1970 - mármore procedente do Paraná;

14. Monumento a Ramos de Azevedo, de Galileo Emendabili - Cidade Universitária, Butantã - 1967 - estátua de bronze com colunas de mármore e base de Granito Itaquera; interessante neste monumento é que um dos blocos constituintes é de Granito Mauá: um dos blocos pode ter-se quebrado devido às diversas mudanças de local onde esteve instalado antes de sua colocação na Cidade Universitária, e ter sido substituído por uma rocha similar, vale ressaltar que a altura das gravações na rocha é praticamente a mesma;

15. Nostalgia, de Francisco Leopoldo da Silva - Praça Prof. Cardim - nos anos de 1920 - estátua de mármore com pedestal do Granito Itaquera;

16. O Ceifador, de Mathurin Moreau - Praça Prof. Resende Poech - 1910 - estátua de mármore com pedestal do Granito Itaquera (reconhecido em locais onde a pintura está descolando, uma vez que a base foi pintada);

17. Monumento às Bandeiras, de Victor Brecheret - Praça Armando de Sales Oliveira, Parque do Ibirapuera - 1953 (levou 6 anos para ser concluído) Granito Cinza Mauá;

18. Monumento a Carlos Gomes, de Luiz Brizzolara - Praça Ramos de Azevedo, Centro - 1922 - estátuas de mármore e de bronze com pedestal de granito rosado (apesar da intensa descoloração assemelha-se ao Granito Vinho Paulista);

19. Obelisco, de Galileo Emendabili - Parque do Ibirapuera - 1960 - travertino;

20. Obelisco da Memória, de Vicente Pereira Ladeira da Memória, Centro - 1814 (o mais antigo monumento de São Paulo) - granito cinza levemente orientado.

As obras de números 17 a 20 são tombadas pelo patrimônio histórico municipal.

A constituição dos monumentos acima analisados são:

- 8 são de mármore, sendo que 1 tem pedestal de calcário fossilífero, 4 têm pedestal de granito cinza (Granito Itaquera) e 1 de granito porfiroclástico;

- 2 são de granito cinza (Cinza Mauá);

- 1 é de travertino; e
- 9 são de bronze, sendo que 2 têm pedestal de Cinza Mauá, 2 têm pedestal de Granito Itaquera, 2 têm pedestal de granito cinza e 3 têm pedestal de granito rosa.

As datas de implantação dos monumentos analisados situam-se entre 1814 a 1970, com concentração entre 1910 e 1928.

Dos monumentos analisados, observa-se que os de pequeno porte são constituídos predominantemente por mármore e por bronze, com pedestais de rochas graníticas, predominando o Granito Itaquera, indicando que no começo do século, poderia haver uma preferência por este granito.

Monumentos de maior expressão são constituídos por granitos, como por exemplo, Monumento às Bandeiras e Duque de Caxias, ambos constituídos pelo Cinza Mauá. A utilização deste granito se torna mais frequente a partir da década de 40 do século passado. Aparentemente, esta foi a rocha preferida do escultor Victor Brecheret na confecção de seus trabalhos, visto o seu uso nos maiores monumentos por ele criados.

O Granito Cinza Mauá, proveniente da cidade de Suzano (SP), foi, e ainda é, muito utilizado em São Paulo. Além dos monumentos Duque de Caxias, Fauno, Monumento às Bandeiras e o pedestal de Camões, é encontrado na Biblioteca Municipal Mário de Andrade e em muitas estações do metrô.

O Granito Itaquera, proveniente de cidade homônima, é constituinte do Monumento a Ramos de Azevedo e pedestal das obras A Menina e o Bezerro, Aretuza, Depois do Banho, Fauno, Nostalgia, O Ceifador, e também foi utilizado em parte da Igreja São Bento, na entrada do Cemitério da Consolação e na base do Teatro Municipal de São Paulo, sendo que neste, também foi utilizado o granito de Lajeado (atualmente Guaianazes). Esses granitos são explorados de longa data, tendo sido muito utilizados na cidade de São Paulo. Azevedo (1945) encontra uma referência à exploração deste granito como Granito Lajeado, datada de 1888.

Não há registro do motivo da substituição do Granito Itaquera pelo Granito Cinza Mauá em monumentos e edifícios da cidade de São Paulo. A causa pode estar relacionada à escassez do corpo de Itaquera ou pela melhor característica tecnológica dos corpos de Mauá e Suzano. Porém, de qualquer forma, na direção sudeste, era o granito mais próximo depois da ocorrência de Itaquera.

Os nomes comerciais dos granitos Vinho Paulista, Rosa Salto e Cinza Mauá estão de acordo com IPT (1990).

RESULTADOS Foram realizadas análises laboratoriais em material coletado nos monumentos, principalmente de fragmentos rochosos, reprecipitado de argamassa de rejunte, depósito superficial e eflorescência.

Os resultados obtidos, de acordo com os métodos analíticos, estão apresentados a seguir.

Microscopia Eletrônica de Varredura e Difração de Raios X Analisaram-se amostras dos seguintes monumentos: Amizade Sirio-Libanesa, O Ceifador, Monumento às Bandeiras, Nostalgia, Monumento a Ramos de Azevedo, Amor Materno, Depois do Banho e Anhanguera. 
AMIZADE SÍRIO-LIBANESA O monumento Amizade Sírio-Libanesa é composto por estátuas de cobre em pedestal de granito rosa. Análise de MEV do reprecipitado da argamassa indica uma cal calcítica com presença de $\mathrm{Cu}$, este oriundo da lixiviação das estátuas de bronze (Fig. 2A). Em fragmento de argamassa, observa-se colônia de micro-organismos (Fig. 3A). Análise de DRX aponta a presença de calcita.

OCEIFADOR O monumento O Ceifador é uma estátua de mármore. Análise de MEV em deposição superficial indica a presença de gipsita (Fig. 2B). O Ca é oriundo da própria rocha e o $\mathrm{S}$ é contribuição da poluição atmosférica. Na preparação do stube, uma amostra foi metalizada com carbono e outro fragmento foi depositado em fita de cobre e metalizado com ouro para verificar a presença de carbono (Fig. 2C), sendo que apresentou também os picos de $\mathrm{Al}$ e Si. Os picos não identificados no gráfico do EDS são de ouro. Uma colônia de micro-organismos pode ser visualizada na figura 3B, com esporos de fungos, detalhados nas figuras 3C, 3D e 3E. EDS dos esporos apontou a presença de $\mathrm{C}, \mathrm{Ca}$ e $\mathrm{O}$.

MONUMENTO ÀS BANDEIRAS Foi obtida uma amostra de argamassa presente em um rejunte na base do Monumento às Bandeiras (Granito Cinza Mauá). O stube foi metalizado com carbono. EDS apontou a presença de calcita, o que foi ratificado por análise de DRX.

NOSTALGIA Do monumento Nostalgia, constituído por mármore, foi coletada uma amostra de fuligem obtida no membro inferior da estátua feminina. Uma amostra foi metalizada com carbono e outra com ouro. EDS aponta a presença de $\mathrm{Si}, \mathrm{Al}, \mathrm{Ca}, \mathrm{K}, \mathrm{O}$, e pouca quantidade de S, Mg e Fe (Fig. 2D). Quando a metalização é com ouro aparece o pico de C. Considerando a constituição da estátua, estes elementos são oriundos, provavelmente, de poluentes atmosféricos. Na fuligem, foram detectadas possíveis estruturas biológicas, tais como cianobactéria, filamentos de fungos, esporos, fibra vegetal e líquen (Figs. 3F e 3G).

MONUMENTO A RAMOS DE AZEVEDO Foi obtida uma amostra de argamassa presente em um rejunte na base do Monumento a Ramos de Azevedo (Granito Itaquera). A amostra foi metalizada com carbono. $\mathrm{O}$ EDS aponta a presença de $\mathrm{Cu}$ e $\mathrm{Pb}$ (Figs. 2E e 2F). É provável que este chumbo seja oriundo de poluentes atmosféricos. Em fragmento da argamassa, observam-se micro-organismos (Fig. 3H).

AMOR MATERNO Foi obtido um fragmento da caiação realizada no monumento de mármore Amor Materno. A análise de DRX indicou presença de calcita. Recentemente, foi realizada a restauração deste monumento, eliminando a "pintura" de cal.

DEPOIS DO BANHO Neste monumento, há a ocorrência de eflorescência na estátua em bronze (Fig. 4), cujo difratograma aponta a presença de gipsita. É pro-
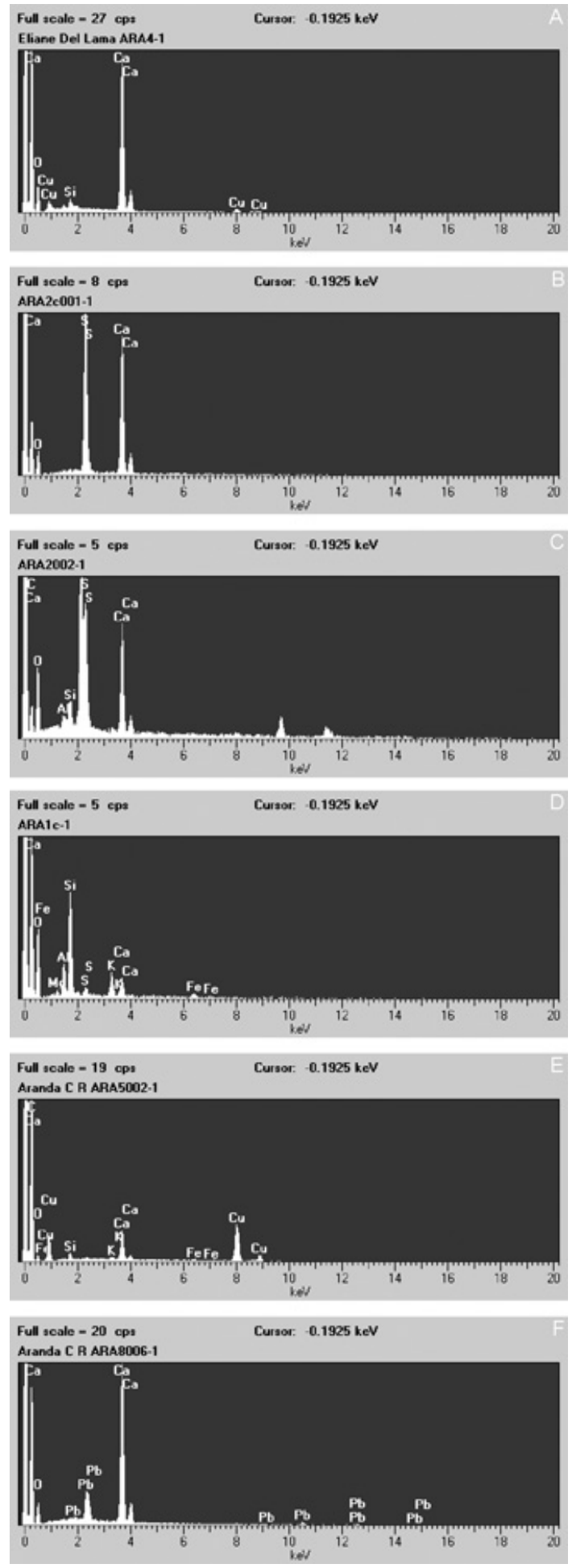

Figura 2 - Monumentos estudados neste trabalho. (A) EDS de calcita do rejunte do monumento Amizade Sírio-Libanesa, notar a presença de cobre. (B) EDS de gipsita em deposição superficial do monumento O Ceifador. (C) Idem a B, com metalização de ouro. (D) EDS de fuligem do monumento Nostalgia. Amostra metalizada com carbono. (E) e (F) EDSs de fragmentos do rejunte do Monumento a Ramos de Azevedo, apontando a presença de calcita e $\mathrm{Cu}$. O cobre é devido à lixiviação do bronze presente em estátuas do monumento. $\operatorname{Em}(F)$, além de calcita, aponta a presença de $\mathrm{Pb}$. 

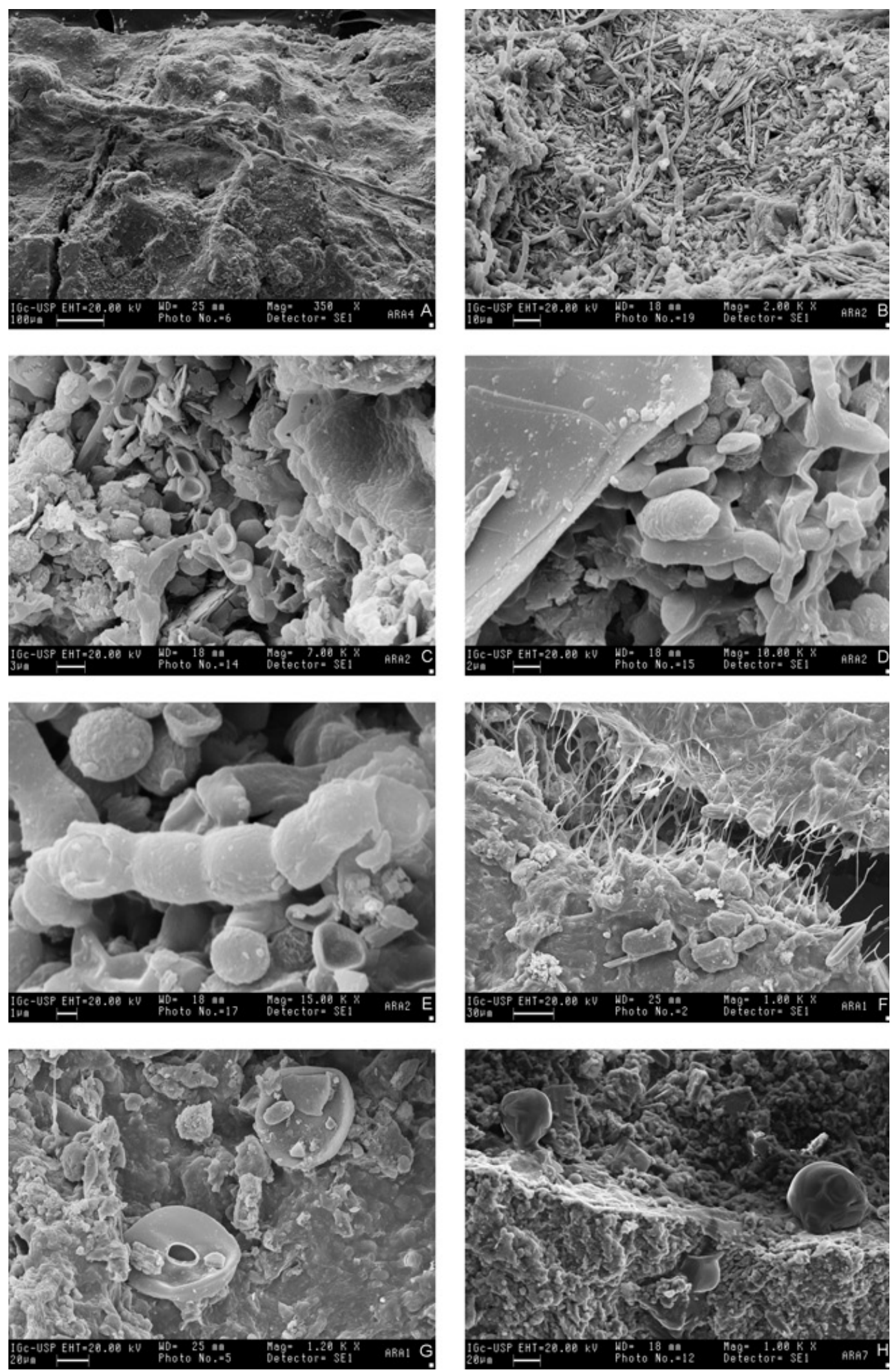

Figura 3 - Imagens de elétrons secundários obtidas no MEV. (A) Colônia de micro-organismos em argamassa do rejunte da Amizade Sírio-Libanesa. (B) a (E) são imagens de deposições superficiais coletadas em O Ceifador. (B) Colônia de micro-organismos: fungo e liquens (alga+fungo). EDS apontou Ca, O e C. (C) Detalhe do esporo de fungo. EDS apontou C, Ca e O. Em EDS geral da amostra, também aparece Si e $S$, este com sinal bastante nitido. (D) Esporos e cianobactérias. Notar material orgânico alóctone sobre a superficie. (E) Esporos, característica estrutural do fungo. EDS apontou $C, C a$ e $O$. (F) e (G) são imagens de fuligem coletada da Nostalgia. (F) Cianobactéria, filamentos de fungos e cristais de calcita. EDS apontou $C, C a, O$ e K. (G) Esporos. EDS apontou $O$, Si, Fe, Al e Ca. (H) Fragmento da argamassa do rejunte do Monumento a Ramos de Azevedo, com dois micro-organismos. EDS aponta C. 
vável que a formação deste sal esteja ligada aos poluentes atmosféricos, uma vez que sulfatos e cálcio não são constituintes desta liga metálica.

Microscopia Petrográfica Foram obtidas amostras para o estudo petrográfico dos seguintes monumentos: Anhanguera e Amizade Sírio-Libanesa, além dos granitos Itaquera e Cinza Mauá, constituintes de vários monumentos aqui estudados. Fotomicrografias dessas rochas são apresentadas nas figuras 5 e 6 .

ANHANGUERA A rocha é constituída de calcário fossilífero (Fig. 5), composta exclusivamente por calcita espática. Ocorre presença de foraminíferos, oóides, bioclastos e intraclastos, não havendo o predomínio de um único grão alobioquímico no arcabouço carbonático de granulação fina.

AMIZADE SÍRIO-LIBANESA O monumento Amizade Sírio-Libanesa é constituído por um granito rosa. Apresenta estrutura maciça, com textura inequigranular média (variando de 1 a $5 \mathrm{~mm}$ ). A mineralogia da rocha é composta por feldspato alcalino (45\%), quartzo (38\%), oligoclásio (16\%), biotita e clorita $(1 \%)$, e traços de minerais acessórios (opacos, apatita, fluorita, zircão e titanita) e minerais de alteração (clorita e sericita).

Os feldspatos alcalinos têm aspecto bem "sujo" e são mesopertíticos, predominando na rocha. $\mathrm{O}$ contato entre os grãos é reto a subangular (Fig. 6A). Em amostra macroscópica, apresenta coloração rosa.

O contato entre os grãos de quartzo são intercrescidos, apresenta forte extinção ondulante e os grãos estão bastante fraturados.

O oligoclásio apresenta cristais tabulares, alguns com zoneamento. Apesar da saussuritização tem aspecto mais límpido que a mesopertita.

A biotita tem coloração marrom, ocorrendo predominantemente de 0,5 a 1,5 mm, mas também ocorre com menor dimensão. Altera-se para clorita.

Os minerais acessórios têm ocorrência muito restrita na rocha. A apatita ocorre como acículas aleatoriamente.

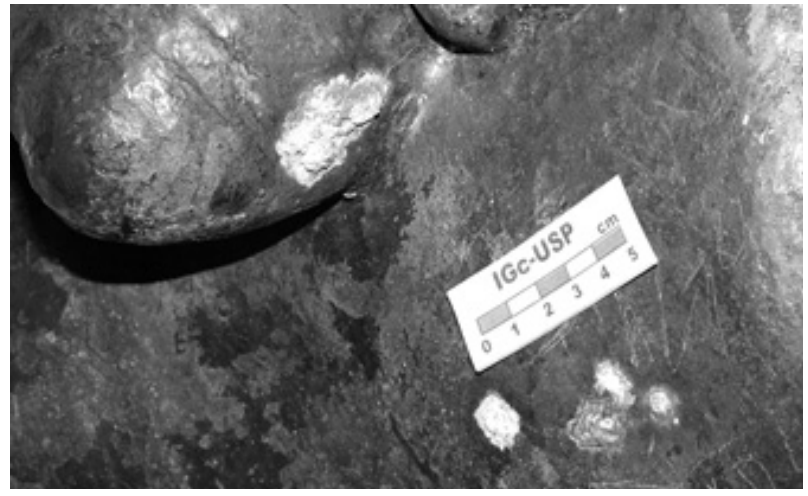

Figura 4 - Eflorescência de gipsita na estátua em bronze Depois do Banho.

O zircão ocorre como minúsculos cristais inclusos na biotita. A titanita ocorre localmente como cristais anedrais. A fluorita (Fig. 6B) é o mineral mais abundante entre os acessórios, ocorre como cristais euhedrais milimétricos.

Os minerais félsicos apresentam recristalização nas bordas como pode ser observado na figura $6 \mathrm{~A}$.

A composição mineral, principalmente pela presença de fluorita, e a estrutura da rocha indicam similaridades deste granito com o Granito Rosa Salto.

GRANITO ITAQUERA O Monumento a Ramos de Azevedo e os pedestais dos monumentos A Menina $e$ o Bezerro, Aretuza, Depois do Banho, Fauno, Nostalgia e $O$ Ceifador são constituídos por um granito cinza comercialmente conhecido como Granito Itaquera, que já não é mais explorado. Classifica-se como Biotita monzogranito no diagrama QAP. Possui uma estrutura levemente orientada e apresenta textura inequigranular, com grande variação granulométrica, conferindo à rocha um aspecto mais heterogêneo e anisótropo. Enclaves micáceos de pequenas dimensões são comuns. Os minerais constituintes da rocha são: oligoclásio (38\%), microclínio (33\%), quartzo (18\%), biotita (9\%), como minerais acessórios ocorrem titanita $(1 \%)$ e traços de
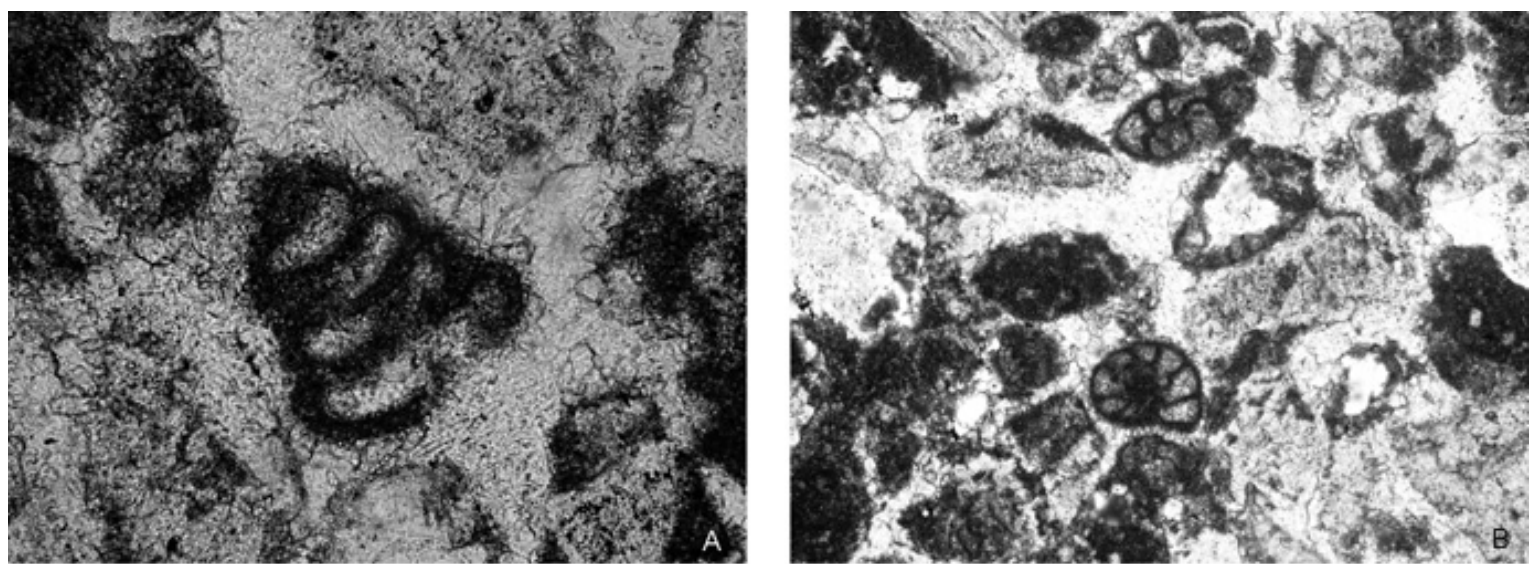

Figura 5 - Fotomicrografias do calcário fossilifero constituinte do Anhanguera. (A) Foraminífero. Aumento: 40x. (B) Molusco na porção central. Aumento: $20 x$. 

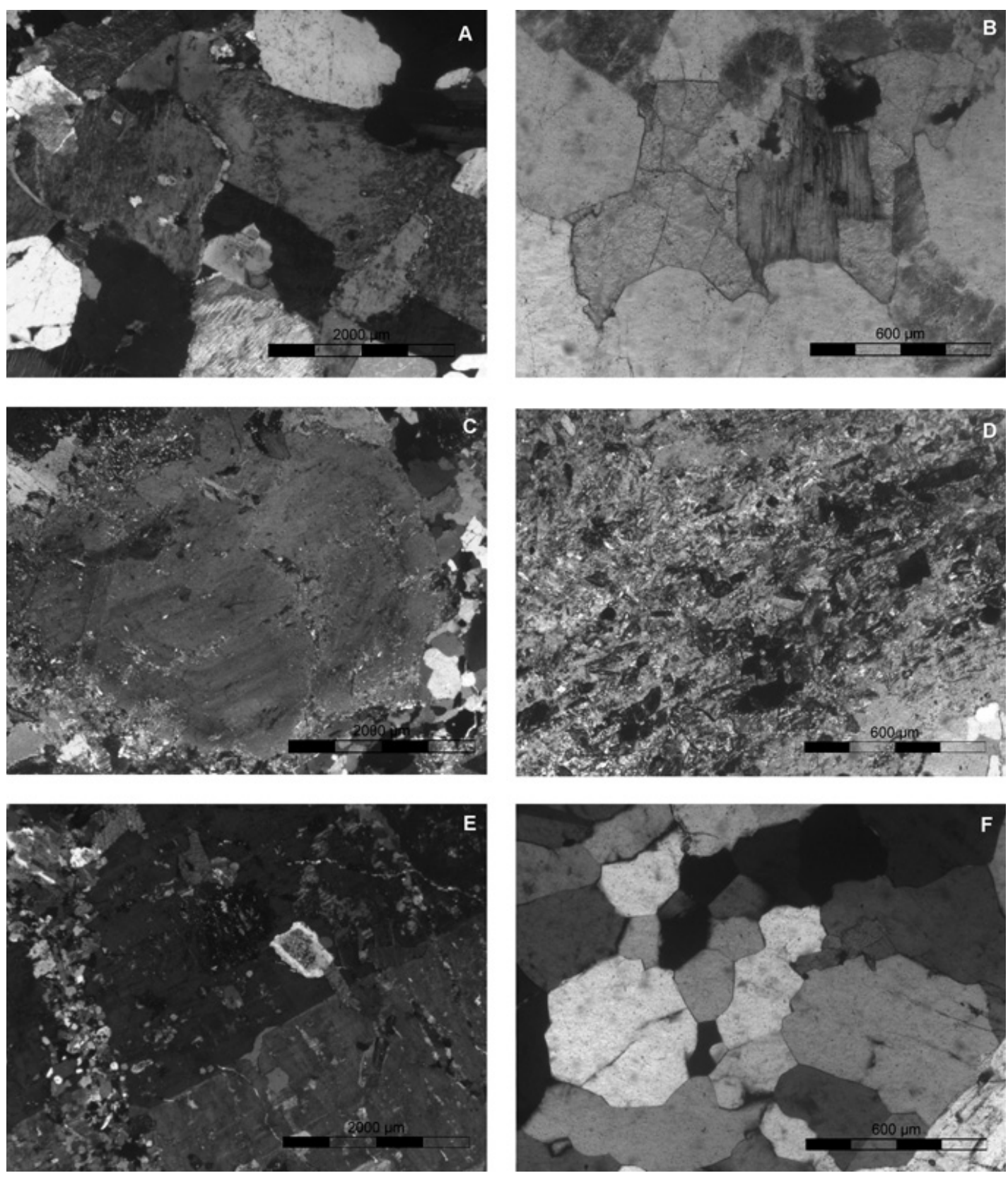

Figura 6 - Fotomicrografias das rochas graniticas. (A) Granito rosa constituinte do monumento Amizade Sírio-Libanesa: recristalização nas bordas de feldspato alcalino. Nicóis cruzados. (B) Cristais milimétricos de fluorita com biotita no centro da foto no granito constituinte do monumento Amizade Sírio-Libanesa. Sem a inserção do analisador. (C) Granito Itaquera: plagioclásio zonado. Nicóis cruzados. (D) Granito Itaquera: epidotização do plagioclásio. Nicóis cruzados. (E) Granito Cinza Mauá: megacristal de microclínio pertítico com inclusão de plagioclásio zonado. Nicóis cruzados. (F) Granito Cinza Maná: poligonização dos grãos de quartzo. Nicóis cruzados.

zircão, apatita e opacos, e como minerais de alteração epidoto (1\%) e traços de clorita, sericita e carbonato.

É bastante evidente a separação entre plagioclásio, com aspecto bem "sujo", e microclínio e quartzo.

O oligoclásio ocorre como cristais subtabulares, sendo muitos deles zonados, apresenta forte processo de saussuritização e também epidotização (Figs. 6C e 6D). Os cristais variam de 1 a $5 \mathrm{~mm}$. Localmente as lamelas de geminação estão curvas indicando defor- mação dos grãos.

O microclínio tem grande variação granulométrica, com cristais submilimétricos até $1 \mathrm{~cm}$. Apresenta geminação em grade marcante e alguns cristais são pertíticos.

O quartzo tem porções recristalizadas, com formação de grãos e subgrãos. O contato dos grãos é lobulado e apresenta forte extinção ondulante, com cristais variando de submilimétricos até $1 \mathrm{~mm}$.

A biotita tem coloração verde a verde amarron- 
zada. Os cristais variam de submilimétricos a $2 \mathrm{~mm}$, ocorrendo em agregados anedrais e alguns cristais subtabulares curvos. No geral, apresenta-se corroída.

$\mathrm{O}$ epidoto ocorre como agregados granulares a cristais subeuhedrais, localmente apresenta formas simplectíticas, variando de minúsculos cristais até 0,5 $\mathrm{mm}$. Está associado ao plagioclásio e/ou à biotita, apresentando-se bastante disseminado na rocha. Também preenche fraturas.

A titanita ocorre como cristais euhedrais variando de submilimétricos a $2 \mathrm{~mm}$. É mais abundante quando associada à biotita e ao epidoto, mas também ocorre inclusa no microclínio.

$\mathrm{O}$ zircão ocorre localmente como inclusões na biotita, provocando halos pleocróicos. A apatita ocorre como cristais prismáticos e hexagonais, mais comumente associada à biotita. A clorita ocorre localmente como alteração da biotita. Sericita e carbonato estão associados ao processo de saussuritização do plagioclásio.

Os minerais constituintes do Granito Itaquera indicam que a rocha foi deformada e alterada hidrotermalmente. A deformação é indicada pela extinção ondulante do quartzo e sua recristalização, as lamelas de geminação curvas do plagioclásio e cristais curvos de biotita. $\mathrm{O}$ hidrotermalismo é evidenciado pela presença marcante de epidoto e a saussuritização do plagioclásio.

GRANITO CINZA MAUÁ Os monumentos Duque de Caxias, Fauno e Monumento às Bandeiras são constituídos por um granito cinza comercialmente conhecido como Granito Cinza Mauá. Classifica-se como Biotita monzogranito no diagrama QAP. Apresenta foliação de fluxo magmático com marcante presença de enclaves micáceos. A textura é porfirítica com megacristais centimétricos de microclínio (Fig. 6E), e é constituído por plagioclásio $(35 \%)$, microclínio (30\%), quartzo $(28 \%)$, biotita $(7 \%)$ e traços de minerais acessórios (allanita, zircão, apatita, titanita, turmalina e opacos) e minerais de alteração (clorita, epidoto, muscovita, sericita e carbonato).

O plagioclásio tem composição de oligoclásio, ocorre como cristais tabulares com granulação variando de 0,5 a $3 \mathrm{~mm}$. Normalmente apresenta geminação polissintética e está saussuritizado.

Os cristais de microclínio ocorrendo como megacristais são euhedrais e normalmente são pertíticos, variando de 1 a $3 \mathrm{~cm}$, e na matriz são anedrais de granulação submilimétrica. É comum a geminação em grade, e apresenta inclusões de plagioclásio e quartzo.

O quartzo apresenta contatos poligonais e está pouco fraturado (Fig. 6F). Os cristais têm granulação de $0,5 \mathrm{~mm}$, mas atinge dimensão milimétrica, localmente exibe extinção ondulante. Ocorrem mirmequitas em contato com o plagioclásio.

Localmente os minerais félsicos acima citados apresentam-se recristalizados, com dimensões submilimétricas.

A biotita tem coloração marrom e ocorre normalmente como agregados tabulares, com cristais variando de 0,1 a $2 \mathrm{~mm}$. As bordas dos grãos, por vezes estão corroídas. Apesar de ser comum em enclaves nes- te granito, não apresenta alteração intempérica, o que não provoca degradação nos monumentos.

Os minerais acessórios normalmente têm formas euhedrais e são submilimétricos. A allanita ocorre como cristais prismáticos e apresenta zoneamento. O zircão ocorre como minúsculos cristais inclusos na biotita provocando halos pleocróicos. A apatita ocorre como cristais predominantemente prismáticos e está associada à biotita e menos comumente está inclusa no microclínio. A titanita ocorre como agregados irregulares a subeuhedrais, inclusos ou associados à biotita. Localmente, atinge $1 \mathrm{~mm}$.

A clorita substitui localmente a biotita. Epidoto, sericita e carbonato ocorrem associados à saussuritização do plagioclásio. $\mathrm{O}$ epidoto também está associado à alteração de allanita, ocorrendo nas bordas deste mineral. A muscovita, quando presente, está substituindo o microclínio.

O Granito Mauá, em comparação com o Granito Itaquera, é muito mais resistente frente ao intemperismo: excetuando os cristais de microclínio, o Granito Mauá tem aspecto mais homogêneo, maior quantidade de quartzo e menor de plagioclásio e mica, além de não ter sido fortemente afetado por processos hidrotermais como o sofrido pelo Granito Itaquera. Essa diferenciação frente aos processos intempéricos, confere menor degradação aos monumentos constituídos pelo Granito Cinza Mauá do que os constituídos pelo Granito Itaquera.

FORMAS DE ALTERAÇÃO OBSERVADAS Foram identificadas as seguintes formas de intemperismo nos monumentos estudados (Tab. 1): depósito superficial (acumulação de materiais alóctones pouco aderentes e de fraca coesão), incrustação (acumulação de material estratiforme aderente ao substrato), alteração cromática (variação local ou ampla de cor), manchas (alteração de cor local e contrastante), alveolização (formação de cavidades), colonização biológica (depósito superficial de natureza biológica), vegetação (aparecimento de plantas), eflorescência (formação de pulverulência de fraca coesão e cor clara), concreção (depósito compacto não paralelo à superfície), escamação (separação de pequenos fragmentos, de espessura inferior a $0,5 \mathrm{~cm}$ ), lascagem (separação de fragmentos, de espessura centimétrica), formação de plaqueta (separação de fragmentos, com grande extensão lateral e de espessura inferior a 0,5 $\mathrm{cm}$ ), ocorrência de fraturas (rompimento que divide o objeto em duas partes distintas) e fissuras (caso particular de fratura, a descontinuidade não atinge o objeto todo). Estas formas dificilmente ocorrem de maneira isolada, geralmente ocorrem associadas e às vezes dificultam o reconhecimento da forma de alteração predominante. A nomenclatura utilizada está de acordo com a terminologia apresentada em Henriques et al. (2005).

A ocorrência de algumas dessas formas de alteração está intrinsicamente relacionada à composição mineral e textural das rochas que constituem os monumentos, e/ou a base deles no caso de monumentos em bronze. Esta relação entre formas de alteração e o material de constituição dos monumentos será indicada no decorrer do texto. 
Tabela 1 - Constituição dos monumentos estudados, os métodos analíticos utilizados e as formas de alteração observadas.

\begin{tabular}{|c|c|c|c|}
\hline Monumento & Material & Método Analítico & Formas de Alteração \\
\hline \multirow{2}{*}{ A Menina e o Bezerro } & Constituição: Mármore & & $\begin{array}{l}\text { Depósito superficial } \\
\text { Mancha }\end{array}$ \\
\hline & Pedestal: Granito Itaquera & Petrografia & $\begin{array}{l}\text { Lascagem } \\
\text { Plaqueta }\end{array}$ \\
\hline $\begin{array}{l}\text { Amizade } \\
\text { Sírio-Libanesa }\end{array}$ & Granito rosa e estátuas de bronze & $\begin{array}{l}\text { MEV e DRX na argamassa } \\
\text { Petrografia }\end{array}$ & $\begin{array}{l}\text { Escamação } \\
\text { Fratura } \\
\text { Incrustação }\end{array}$ \\
\hline \multirow{2}{*}{ Amor Materno } & Constituição: Mármore & DRX em fragmento de caiação & Lascagem \\
\hline & Pedestal: Granito porfiroclástico & & Recentemente restaurado \\
\hline \multirow[b]{2}{*}{ Anhanguera } & Constituição: Mármore & & $\begin{array}{l}\text { Alveolização } \\
\text { Depósito superficial }\end{array}$ \\
\hline & Pedestal: Calcário fossilífero & Petrografia & Fissura \\
\hline \multirow{2}{*}{ Aretuza } & Constituição: Mármore & & Limpeza recente \\
\hline & Pedestal: Granito Itaquera & Petrografia & Lascagem \\
\hline \multirow{2}{*}{ Camões } & Constituição: Bronze & & \multirow{2}{*}{ Em restauração } \\
\hline & $\begin{array}{l}\text { Pedestal: Granito Mauá } \\
\text { Constituição: Bronze }\end{array}$ & Petrografia & \\
\hline Cervantes & Pedestal: Granito rosa & & Mancha \\
\hline \multirow{2}{*}{ Depois do Banho } & Constituição: Bronze & DRX em eflorescência & Eflorescência \\
\hline & Pedestal: Granito Itaquera & Petrografia & Lascagem \\
\hline Duque de Caxias & Granito Mauá e estátua de bronze & Petrografia & $\begin{array}{l}\text { Concreção } \\
\text { Fissura } \\
\text { Incrustação } \\
\text { Mancha } \\
\text { Vegetação }\end{array}$ \\
\hline \multirow{2}{*}{ Fauno } & Constituição: Granito Mauá & Petrografia & \multirow{2}{*}{$\begin{array}{l}\text { Sem formas de alteração } \\
\text { aparente }\end{array}$} \\
\hline & Pedestal: Granito Itaquera & Petrografia & \\
\hline Fonte Monumental & $\begin{array}{l}\text { Mármore com ornamentações de } \\
\text { bronze }\end{array}$ & & $\begin{array}{l}\text { Alveolização } \\
\text { Lascagem } \\
\text { Mancha }\end{array}$ \\
\hline \multirow{2}{*}{$\begin{array}{c}\text { Glória Imortal aos } \\
\text { Fundadores de São Paulo }\end{array}$} & $\begin{array}{l}\text { Constituição: Bronze com coluna } \\
\text { de sienito vermelho }\end{array}$ & & \\
\hline & Pedestal: Granito cinza & & Fissura e plaqueta \\
\hline \multirow[b]{2}{*}{$\begin{array}{l}\text { Monumento a Ramos de } \\
\text { Azevedo }\end{array}$} & $\begin{array}{l}\text { Marmore } \\
\text { Constituição: Bronze com colunas } \\
\text { de mármore }\end{array}$ & MEV na argamassa & $\begin{array}{l}\text { Fissura } \\
\text { Colonização biológica } \\
\text { Mancha }\end{array}$ \\
\hline & Pedestal: Granito Itaquera & Petrografia & $\begin{array}{l}\text { Colonização biológica } \\
\text { Fissura e fratura } \\
\text { Incrustação } \\
\text { Lascagem }\end{array}$ \\
\hline \multirow[t]{2}{*}{ Nostalgia } & Constituição: Mármore & MEV em depósito superficial & $\begin{array}{l}\text { Alteração cromática } \\
\text { Alveolização } \\
\text { Depósito superficial }\end{array}$ \\
\hline & Pedestal: Granito Itaquera & Petrografia & Lascagem \\
\hline \multirow[t]{2}{*}{ O Ceifador } & Constituição: Mármore & MEV em depósito superficial & $\begin{array}{l}\text { Depósito superficial } \\
\text { Mancha }\end{array}$ \\
\hline & Pedestal: Granito Itaquera & & O pedestal está pintado \\
\hline Monumento às Bandeiras & Granito Mauá & $\begin{array}{l}\text { MEV e DRX na argamassa } \\
\text { Petrografia }\end{array}$ & $\begin{array}{l}\text { Escamação } \\
\text { Fissura } \\
\text { Mancha } \\
\text { Vegetação }\end{array}$ \\
\hline \multirow{2}{*}{$\begin{array}{l}\text { Monumento a Carlos } \\
\text { Gomes }\end{array}$} & $\begin{array}{l}\text { Constituição: Estátuas de } \\
\text { mármore e de bronze }\end{array}$ & & Alveolização \\
\hline & Pedestal: Granito rosado & & $\begin{array}{l}\text { Alteração cromática } \\
\text { Lascagem }\end{array}$ \\
\hline Obelisco & Travertino & & Mancha \\
\hline Obelisco da Memória & Granito cinza levemente orientado & & $\begin{array}{l}\text { Alteração cromática } \\
\text { Escamação } \\
\text { Fissura } \\
\text { Plaqueta }\end{array}$ \\
\hline
\end{tabular}

Algumas destas formas estão associadas ao ambiente, por efeito da poluição, umidade, ação de microorganismos e intervenções realizadas.

O efeito da poluição origina o depósito superficial de coloração preta e espessura submilimétrica, observa- do nos monumentos A Menina e o Bezerro, Anhanguera, Nostalgia e $O$ Ceifador. Esse depósito é proveniente de poeira, fuligem da queima de óleo combustível e partículas advindas da descarga dos veículos. Eventualmente, podem se instalar aí micro-organismos, que, após a sua 
morte, também adquirem coloração escura. A poluição também está associada à presença de eflorescência, como observada no monumento Depois do Banho.

$\mathrm{O}$ efeito da umidade é notado nas formas colonização biológica e vegetação, observadas em muitos monumentos na forma de crescimento de liquens e pequenas plantas. Outra forma originada é a concreção, que aparece em monumentos com partes rejuntadas por argamassa, que pode ser lixiviada e reprecipitada, podendo assumir formas estalactíticas. Por processo semelhante, aparece a incrustação, principalmente em monumentos que têm partes em bronze: o cobre presente na liga é lixiviado e depositado nas argamassas do rejunte, que reage com o carbonato, originando carbonato de cobre. Este se deposita no próprio rejunte ou na superfície das rochas, conferindo-lhe cores esverdeadas.

A alteração cromática e a mancha podem ocorrer pela presença de algum mineral constituinte da rocha ou pelo uso de produtos de limpeza inadequados para as rochas em questão. A pirita e a magnetita, por exemplo, formam uma auréola amarelada-alaranjada quando alteradas que contrastam com os minerais adjacentes. Com extensão mais ampla, produtos de limpeza não recomendados podem manchar a rocha originando uma coloração amarelo clara.

As formas de alteração diretamente ligadas ao tipo de rocha são: alveolização, escamação, lascagem, plaqueta, fraturas e fissuras.

A alveolização, formação de cavidades com área de abertura para o exterior, é uma forma de intemperismo típica das rochas carbonáticas, como bem evidente no monumento Fonte Monumental, mas também pode ser observado nos monumentos Anhanguera, Monumento a Carlos Gomes e Nostalgia. Em monumentos que ficam expostos a céu aberto, como é o caso dos monumentos estudados aqui, não há como impedir a ocorrência deste processo. Essa forma de alteração também pode aparecer em rochas areníticas, como se observa nos arenitos na Flona de Ipanema, Iperó, SP (Fig. 7), constituintes da fachada de revestimento do Teatro Municipal de São Paulo.

As formas escamação, lascagem e plaqueta estão diretamente associadas à estrutura e/ou à composição mineral da rocha. Todas se referem à formação e desprendimento de fragmentos achatados, que diferem na espessura ou no comprimento do fragmento. A concentração de minerais placóides favorece o aparecimento de escamação, pois esses minerais alteram-se mais rapidamente que as encaixantes. Os enclaves de biotita do Granito Itaquera são exemplos que podem desencadear o aparecimento desta forma de alteração. Para as rochas que apresentam estruturas orientadas, deve-se atentar para a direção do corte: se esta for paralela à estrutura, pode favorecer e acelerar o processo intempérico e assim originar a ocorrência das formas lascagem e plaqueta. É comum aparecer estas formas de alteração em rochas granitóides, independente da quantidade de micas. A presença de descontinuidades nas rochas também auxilia no aparecimento destas formas de alteração. E no caso em particular da plaqueta,

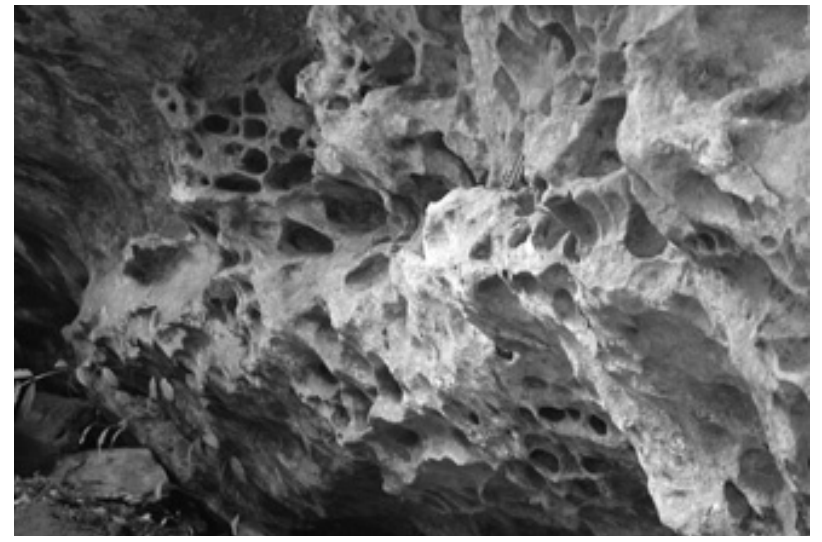

Figura 7 - Alveolização observada em arenitos na Flona de Ipanema, Iperó, SP.

seu surgimento pode ser devido à constante elevação de temperatura, pelas fogueiras que moradores de ruas fazem próximas aos monumentos.

Escamação foi observada nos monumentos: Amizade Sírio-Libanesa, Monumento às Bandeiras e Obelisco da Memória. Lascagem foi observada nos monumentos: A Menina e o Bezerro, Amor Materno, Aretuza, Depois do Banho, Fonte Monumental, Monumento a Carlos Gomes, Monumento a Ramos de Azevedo e Nostalgia. Plaqueta foi observada nos monumentos: $A$ Menina e o Bezerro, Glória Imortal aos Fundadores de São Paulo e Obelisco da Memória.

É muito comum a presença de fraturas e/ou fissuras nas rochas, e salvo casos de vandalismo, é uma alteração herdada da época de formação da rocha. A ocorrência de fissuras permite a percolação de água, o que favorece e acelera os processos intempéricos no interior dos monumentos. Foram observadas nos monumentos: Amizade Sírio-Libanesa, Monumento a Ramos de Azevedo, Anhanguera, Duque de Caxias, Glória Imortal aos Fundadores de São Paulo, Mãe, Monumento às Bandeiras, Monumento a Ramos de Azevedo e Obelisco da Memória.

DISCUSSÃO DOS RESULTADOS A análise dos monumentos selecionados para estudo neste trabalho, indica que o Granito Itaquera e o Granito Cinza Mauá são as principais rochas constituintes desses monumentos.

Devido à estrutura e a composição mineralógica, o Cinza Mauá mostra-se como mais adequado para os monumentos, sendo que efetivamente está melhor preservado que os confeccionados com o Granito Itaquera. O Granito Mauá foi a rocha preferida do artista Victor Brecheret, observado nos monumentos de sua autoria.

Além das características próprias dos materiais rochosos, a degradação pelos processos intempéricos causada pelas águas das chuvas, variação de temperaturas devido à insolação, outros fatores também atuam na degradação da rocha, como micro-organismos e a poluição.

É comum a presença de micro-organismos nos monumentos analisados, seja como deposição superficial ou nas argamassas.

Os poluentes atmosféricos também estão pre- 
sentes nos monumentos, principalmente na forma de sulfato: a presença de gipsita em estátuas de mármore e de bronze atestam sua origem alóctone. O enxofre provavelmente é oriundo dos poluentes atmosféricos derivado da queima de combustíveis fósseis. Outros contaminantes foram detectados, como por exemplo, $\mathrm{Pb}$.

Foi constatado que a cal calcítica foi a utilizada extensivamente como argamassa de rejunte dos monumentos analisados. A presença de $\mathrm{Cu}$ é detectada nas argamassas de monumentos com pedestal de pedra e estátuas de bronze, e que é oriundo da lixiviação desta liga metálica.

CONCLUSÕES Projetos de conservação e restauração de materiais pétreos envolvem o conhecimento das características da rocha, do seu estado de alteração e das causas e mecanismos de deterioração. O primeiro passo é o mapeamento das formas de alteração.

A manutenção e a limpeza dos monumentos devem sempre ser efetuadas com o objetivo de se preservar a superfície do objeto e valorizar o bem patrimonial, com eliminação apenas das substâncias nocivas da superfície. As formas de alteração: depósito superficial, incrustação, manchas e colonização biológica, podem esteticamente prejudicar a leitura do monumento, mas na decisão se elas devem ser retiradas ou não, tem-se que avaliar se o método de eliminação não prejudicará mais o monumento.

Por isso, a presença de um geólogo para se efetuar um diagnóstico correto é necessária, e por consequência, uma intervenção sem efeitos colaterais, e principalmente que essa intervenção seja mínima, visando preservar o valor histórico da obra.

Não é possível estabelecer previsões e padronizações quanto ao ritmo da alteração, devido à complexidade do processo de intemperismo e das variáveis que o integram.

No geral, o estado de conservação dos monumentos varia de ruim a muito bom. Os monumentos aqui analisados são relativamente jovens, e uma vez que eles foram construídos com rochas sãs, as condições intempéricas ainda não foram suficientes para danificá-los. E apesar das alterações intempéricas existentes, é a alteração antrópica, representada por vandalismo (quebras, roubo de partes do monumento e principalmente pichações), o principal fator de degradação dos monumentos.

Portanto, além dos trabalhos de conservação e restauro provocado pela alteração inerente aos monumentos, deve-se conscientizar a população, por meio de programas de educação patrimonial da importância desses monumentos para a preservação da nossa herança cultural.

\section{Referências}

Azevedo A.E. de. 1945. Subúrbios orientais de São Paulo. Tese de concurso à cadeira de Geografia do Brasil da Faculdade de Filosofia, Ciências e Letras da Universidade de São Paulo, 184 p.

Baptista-Neto J.A., Smith B.J., McAllister J.J., Silva M.A.M., Castanheira F.S. 2006. Surface modification of a granite building stone in central Rio de Janeiro. An. Acad. Bras. Cienc., 78:317-330.

Del Lama E.A. 2006. Geologia e Herança Cultural. Rev. Bras. Geoc., 36:379-381.

Del Lama E.A., Szabó G.A.J., Dehira L.K., Kihara Y. 2008. Impacto do intemperismo no arenito de revestimento do Teatro Municipal de São Paulo. Geologia USP, Série Cientifica, 8:75-86. Disponível em http://geologiausp. igc.usp.br/geologiausp/sc1/art.php?artigo=703. Acessado em 13 nov 2008.

Henriques F.M.A., Delgado Rodrigues J., Aires-Barros L., Proença N. 2005. Materiais pétreos e similares Terminologia das formas de alteração e degradação. LNEC, Lisboa, 39 p.

INSTITUTO DE PESQUISAS TECNOLÓGICAS (IPT) 1990. Catálogo das rochas ornamentais do estado de São Paulo. São Paulo, 123 p.

Philipp R.P. \& Di Benedetti V. 2007. Análise e avaliação da deterioração do revestimento de mármore da cúpula da catedral Metropolitana de Porto Alegre. Rev. Bras. Geoc., 37:650-659.

Reys A.C., Del Lama E.A., Dehira L.K. 2007. Monumentos da cidade de São Paulo: formas de alteração e conservação. Revista CPC (Centro de Preservação Cultural da USP), 5:93-122. Disponível em http://www.usp.br/cpc/v1/ php/wf07 revista interna.php?id revista $=9 \&$ id conteudo $=\overline{2} 2 \&$ tipo $=\overline{7}$. Acessado em $1 \overline{3}$ nov 2008 .

Sant'ana D.C.F., Carvalho C.R., Tannus M.B., Santos A.F.B., Pedralli G., Morimoto T., Agrizzi E.J., Ribeiro L.I. 2002. Assessment of the state of conservation of the historic heritage of the Convent of Nossa Senhora da Penha, located in the town of Vila Velha, in the state of Espírito Santo, Brazil. In: Garg V.K. \& Souza Jr. P.A.de (eds.) International Workshop on Air Quality in Industrialized Urban Centers, 1, Proceedings, p. 204-230.

Silva V.da S. 2007. Alteração de rochas e a conservação do patrimônio arquitetônico: estudo de caso do pórtico da Igreja do Outeiro da Glória. Dissertação de Mestrado, Instituto de Geociências, Universidade Federal do Rio de Janeiro, 160 p.

Silva M.E.da \& Roeser H.M.P. 2003. Mapeamento de deteriorações em monumentos históricos de pedra-sabão em Ouro Preto. Rev. Bras. Geoc., 33:329-336.

Stern A.G., Riccomini C., Fambrini G.L., Chamani M.A.C. 2006. Roteiro geológico pelos edifícios e monumentos históricos do centro da cidade de São Paulo. Rev. Bras. Geoc., 36:704-711.

Teixeira R.B., Silva V.F.da, Barroso E.V. 2008. O Martelo de Schmidt como ferramenta de avaliação da degradação de rochas de cantaria em prédios históricos. In: ABGE, Congr. Bras. Geol. Eng. e Amb., 12, Anais, CD-Rom.

Manuscrito ID 12881

Submetido em 24 de novembro de 2008 Aceito em 12 de agosto de 2009 